\title{
Produção de Forragem do Capim-Tanzânia (Panicum maximum Jacq. cv. Tanzânia-1) Pastejado em Diferentes Alturas ${ }^{1}$
}

\author{
Clovenilson Cláudio Perissato Cano ${ }^{2}$, Ulysses Cecato ${ }^{3^{*}}$, Marcos Weber do Canto ${ }^{3}$, \\ Anneliese Biagi Rodrigues ${ }^{4}$, Clóves Cabreira Jobim ${ }^{3}$, Augusto Manoel Rodrigues ${ }^{4}$, \\ Sandra Galbeiro ${ }^{4}$, Willian Gonçalves do Nascimento ${ }^{5}$
}

\begin{abstract}
RESUMO - Objetivou-se, com este experimento, avaliar a massa de forragem (MF), massa de lâmina verde (MLV), massa de colmo + bainha verde (MCV), massa de material morto (MMM), massa de forragem verde (MFV), relação folha/colmo (F/C), taxa de acúmulo de massa seca (TAMS), acúmulo de massa de forragem (AMF), índice de área foliar (IAF), porcentagem de solo descoberto (SD) e porcentagem de solo coberto com liteira (SCL) em pastagem de capim-Tanzânia (Panicum maximum Jacq. cv. Tanzânia-1) manejada em quatro alturas do dossel forrageiro (20, 40, 60 e 80 cm). O método de pastejo utilizado foi o de lotação contínua e taxa de lotação variável, com novilhos da raça Nelore com peso médio de $340 \mathrm{~kg}$. Utilizou-se o delineamento experimental inteiramente casualizado com duas repetições e realizaram-se cinco avaliações. MLV, MCV, MMM, MFV, MF, IAF, TAMS e AMF aumentaram com o avanço da altura do dossel, sendo que a porcentagem de SD, SCL e material morto diminui em pastos mais altos. O manejo do capim-Tanzânia nas alturas de 40 e 60 cm, apresentou as melhores respostas de composição morfológica, garantindo boa oferta de folhas, de cobertura do solo e taxa de acúmulo de massa seca. As alturas de 20 e 80 cm não devem ser recomendadas para o manejo do capim-Tanzânia quando o objetivo for produção com qualidade e quantidade.
\end{abstract}

Palavras-chave: acúmulo de massa seca, índice de área foliar, massa de lâminas verdes, solo descoberto, relação folha/colmo

\section{Forage Production of Tanzaniagrass (Panicum maximum Jacq. cv. Tanzania-1) Grazed at Different Heights}

\begin{abstract}
This experiment was conducted out to evaluate the forage mass (FM), green leaf lamina mass (GLLM), green stem + leaf sheath mass (GSSM), mass of dead material (MDM), green forage mass (GMF), total forage mass (TFM), leaf/stem ratio (L/S), dry matter accumulation rate (DMAR), leaf area index (LAI), \% of bare soil (BS) and litter cover percentage (LCP) in Tanzaniagrass pasture (Panicum maximum Jacq. cv. Tanzania-1) managed at four different sward heights (20, 40, 60 and $80 \mathrm{~cm}$ ). The grazing method was the continuous stocking with variable stocking rate, and the grazing animals were Nellore steers with average weight of $340 \mathrm{~kg}$. The completely randomized design was used with two replications and five evaluation periods were performed. The GLLM, GSSM, MDM, GMF, FM, LAI, DMAR, and TFM increased by increasing of the pasture height, the percentage of NCS, SCWL and dead material decreased with the pasture height. Tanzaniagrass management, based on the pasture height from 40 to 60 cmshowed good morphologic composition and high leaves availability for grazing, good ground cover and dry matter accumulation rate, while the heights of 20 and $80 \mathrm{~cm}$ shall not be recommended for the Tanzania grass management when the objective is high production of forage quality.
\end{abstract}

Key Words: accumulation of green dry matter, bare ground, leaf area index, leaf/stem ratio, total forage mass

\section{Introdução}

Entre os cultivares de Panicum maximum, o capim-Tanzânia-1 apresenta, como principais características, alto potencial de produção de massa seca, bom valor nutritivo (Corsi \& Santos, 1995; Machado et al., 1998; Rego, 2001) e alta capacidade de adap- tação e produção de forragem na região noroeste do Paraná (Cecato et al., 2000).

Para manter a pastagem sempre em nível adequado de biomassa para os animais, a altura de pastejo é ideal para o monitoramento da biomassa de forragem (Bircham \& Hodgson, 1983; Canto et al., 2001).

\footnotetext{
${ }^{1}$ Parte integrante da dissertação do primeiro autor.

2 Mestre em Zootecnia - UEM (canozoo@hotmail.com).

${ }^{3}$ Professores do Departamento de Zootecnia - UEM. Av. Colombo, 5.790, 87020-900, Maringá-PR. Pesquisadores do CNPq (ucecato@uem.br).

4 Acadêmicos de Pós-Graduação - Mestrado, PPZ - UEM.

${ }^{5}$ Aluno de doutorado em Zootecnia, PPZ-UEM. Av. Colombo, 5.790, 87020-900, Maringá-PR.

* Bolsista do CNPq.
} 
A altura média das plantas na pastagem indica a quantidade de forragem em oferta (Penning et al., 1991; Almeida et al., 2000; Fagundes et al., 1999a), pois pode determinar diferenças no desempenho animal e na quantidade de produto animal comercializável por unidade de área (Mott \& Moore, 1985; Maraschin 1994).

Segundo Forbes (1988) e Brâncio et al. (2000), existe alta correlação entre o consumo de forragem pelos animais em pastejo e a altura do dossel forrageiro. Em pastagens tropicais onde se adota o método de lotação contínua, com bovinos de corte, ainda se desconhece a relação funcional entre a altura do dossel e o ganho de peso médio diário, o que demonstra que o uso da pastagem conforme a altura do dossel forrageiro em espécies tropicais necessita ser investigado.

A produção de forragem é resultante das condições climáticas e do solo, da freqüência e intensidade de corte ou de pastejo (Cecato, 1993; Santos et al., 1999), bem como das características intrínsecas de cada cultivar. Além disso, essas variam também com aplicação de fertilizantes, principalmente os nitrogenados (Hodgson, 1990; Cecato, 1993), que podem promover rápido crescimento, com reflexos na produção de colmos e de folhas e no consumo de forragem. Plantas do gênero Panicum, em boas condições de solo e de clima, produzem anualmente de 10 a 20 t/ha de MS (Cecato et al., 2000), com produções de até 50 t/ha de MS, em condições excepcionais (Bogdan 1977).

Segundo Herling (1995), nas regiões tropicais, durante a estação das chuvas, a temperatura, a luz e a umidade não constituem fatores limitantes ao desenvolvimento das plantas forrageiras e, dependendo das condições de manejo, pode-se obter elevada taxa de acúmulo (kg/ha/dia de MS) e produção de massa seca (kg/ha de MS) das mesmas, o que não se observa na estação seca. Todavia, altas taxas de acúmulo são obtidas em função de altas taxas fotossintéticas, com elevadas taxas respiratórias e de senescência.

Para Panicum maximum, Humpherys (1978) considerou a faixa de IAF ótima ou crítica entre 3 e 5. Abaixo desse valor, a taxa de acúmulo era reduzida, mas alcançava valor ótimo, se estabilizava ou caía, em decorrência do sombreamento da base das plantas. Contudo, segundo Hodgson (1990), se o IAF do dossel forrageiro estiver próximo do nível ótimo, haverá adequada capacidade para intercepção de luz, pois a produção de massa seca depende da proporção de luz incidente interceptada e de sua eficiente utilização.

A área foliar que permanece após o pastejo ou corte é de grande importância para a rebrotação (Humpherys, 1975), pois afeta, por meio da fotossíntese, a velocidade de recuperação da pastagem. Todavia, quando as plantas são submetidas a desfolhações freqüentes, há pouca competição por luz, em razão de constante remoção de área foliar pelos animais (Lemaire, 2001).

Conduziu-se este estudo com o objetivo de avaliar o efeito das alturas de dossel forrageiro de 20, 40, 60 e $80 \mathrm{~cm}$ sobre a massa de forragem, a taxa de acúmulo, a produção e a composição morfológica da MS produzida em pastos.

\section{Material e Métodos}

O experimento foi conduzido em Astorga - PR, região noroeste do Paraná, no período de 23 de dezembro de 1999 a 29 de abril de 2000. A entrada dos animais na área ocorreu em 23 de dezembro de 1999, sendo a primeira avaliação efetuada em 04 de janeiro de 2000 (dia zero do período de avaliação) e a última, em 29 de abril de 2000 (112 dias de avaliação).

O clima da região é "Cfa", subtropical úmido, mesotérmico, com verões quentes e geadas pouco freqüentes. As coordenadas geográficas aproximadas do local do experimento são $51^{\circ} 57^{\prime}$ de Longitude Oeste, $23^{\circ} 25^{\prime}$ de Latitude Sul e 545 metros de altitude (Corrêa, 1996). Os dados de temperatura e de precipitação pluviométrica (máxima, mínima e média) observados durante o experimento são encontrados na Tabela 1.

O solo da área experimental é do tipo Latossolo Vermelho Eutroférrico, com as seguintes características de fertilidade: $\mathrm{pH}-\mathrm{H}_{2} \mathrm{O}=6,9, \mathrm{Al}+++=0,00 *$, $\mathrm{H}++\mathrm{Al}+++=3,13^{*}, \mathrm{Ca}+++\mathrm{Mg}++=7,16^{*}, \mathrm{Ca}++=$ $5,88^{*}, \mathrm{~K}+=0,60$ cmolc $\mathrm{dm}^{-3}(*), \mathrm{P}=3 \mathrm{mg} \mathrm{dm}^{-3} \mathrm{e}$ $\mathrm{C}=15,96 \mathrm{~g} \mathrm{dm}^{-3}$. Por ocasião da semeadura da pastagem (setembro de 1996), foram aplicados $180 \mathrm{~kg} / \mathrm{ha}$ de superfosfato e $60 \mathrm{~kg} / \mathrm{ha}$ de cloreto de potássio. No período de dezembro de 1998 a março de 1999, foram aplicados $250 \mathrm{~kg} / \mathrm{ha}$ de $\mathrm{N}$ na forma de uréia, parcelados em quatro vezes (50, 80, 70 e $50 \mathrm{~kg} / \mathrm{ha}$ de $\mathrm{N}$ ) e aplicados nos meses de dezembro, janeiro, fevereiro e março, respectivamente. Em outubro de 1999, foram aplicados $300 \mathrm{~kg} / \mathrm{ha}$ da fórmula 0-20-20 (NPK) e mais $600 \mathrm{~kg} / \mathrm{ha}$ de superfosfato simples para adubação de180 kg/ha de $\mathrm{P}_{2} \mathrm{O}_{5}$ e $60 \mathrm{~kg} / \mathrm{h}$ a de $\mathrm{K}_{2} \mathrm{O}$. No período 
Tabela 1 - Precipitação pluviométrica e temperaturas médias durante o período experimental Table 1 - Mean temperature and rainfall, during the experimental period

\begin{tabular}{lcccc}
\hline $\begin{array}{l}\text { Mês } \\
\text { Month }\end{array}$ & $\begin{array}{c}\text { Precipitação }(\mathrm{mm}) \\
\text { Rainfall }(\mathrm{mm})\end{array}$ & \multicolumn{3}{c}{$\begin{array}{c}\text { Temperatura }\left({ }^{\circ} \mathrm{C}\right) \\
\text { Temperature }\left({ }^{\circ} \mathrm{C}\right)\end{array}$} \\
\cline { 3 - 5 } & & $\begin{array}{c}\text { Máxima } \\
\text { Maximum }\end{array}$ & $\begin{array}{c}\text { Mínima } \\
\text { Minimum }\end{array}$ & $\begin{array}{c}\text { Média } \\
\text { Mean }\end{array}$ \\
\hline Novembro/99 (November 99) & 46,7 & 29,3 & 17,4 & 24,5 \\
Dezembro/99 (December 99) & 280,9 & 31,0 & 20,0 & 26,6 \\
Janeiro/2000 (January 00) & 242,8 & 31,0 & 20,6 & 26,4 \\
Fevereiro/2000 (February 00) & 278,4 & 28,9 & 20,2 & 25,2 \\
Março/2000 (March 00) & 130,3 & 29,0 & 19,8 & 24,7 \\
Abril/2000 (April 00) & 32,0 & 29,1 & 18,8 & 24,4 \\
\hline
\end{tabular}

Fonte: Estação Climatológica Principal de Maringá.

de dezembro de 1999 a fevereiro de 2000, foram aplicados $250 \mathrm{~kg} / \mathrm{ha} \mathrm{N}$ na forma de uréia, parcelados em quatro vezes $(50,80,70$ e $50 \mathrm{~kg} / \mathrm{ha}$ de $\mathrm{N})$, aplicados nos meses de dezembro, janeiro, início e final de fevereiro, respectivamente.

Este experimento foi conduzido em área já estabelecida de capim-Tanzânia em setembro de 1998 e dividida em oito unidades experimentais (piquetes), com área variável de 1,04 ha a 1,27 ha, ocupando uma área total de 8,9 ha. Cada piquete possuía cochos para sal mineral e reservatório de água. Uma área de 6,0 ha, adjacente à área experimental e com o mesmo cultivar de gramínea forrageira, foi destinada à manutenção dos animais reguladores da taxa de lotação dos pastos.

Os tratamentos estudados foram quatro alturas de dossel forrageiro: $\mathrm{T} 1=20 \mathrm{~cm}, \mathrm{~T} 2=40 \mathrm{~cm}, \mathrm{~T} 3=60 \mathrm{~cm}$ e $\mathrm{T} 4=80 \mathrm{~cm}$. Para a análise de regressão, foi utilizada a altura média real estimada nas unidades experimentais, correspondendo às alturas do dossel: $\mathrm{T} 1 \mathrm{R} 1=22, \mathrm{~T} 1 \mathrm{R} 2=23, \mathrm{~T} 2 \mathrm{R} 1=39, \mathrm{~T} 2 \mathrm{R} 2=41, \mathrm{~T} 3 \mathrm{R} 1=45$, $\mathrm{T} 3 \mathrm{R} 2=56, \mathrm{~T} 4 \mathrm{R} 1=62$ e $\mathrm{T} 4 \mathrm{R} 2=69 \mathrm{~cm}$. Estes tratamentos foram avaliados sob pastejo contínuo e taxa de lotação variável. O delineamento experimental utilizado foi o inteiramente casualizado, com duas repetições, totalizando oito unidades experimentais.

Os animais utilizados no experimento foram novilhos castrados Nelore, com dois anos de idade e peso vivo médio inicial de $340 \mathrm{~kg}$, provenientes do rebanho da Fazenda Nossa Senhora Aparecida. Foram utilizados quatro animais testers por piquete mais os animais reguladores, por meio da técnica put and take, colocados ou retirados conforme nível da altura do dossel (Mott \& Lucas, 1952).

O ajuste da taxa de lotação foi feito a cada duas semanas, conforme a altura do dossel requerida em cada unidade experimental. A altura do dossel foi estimada com o auxílio de uma régua de $2,0 \mathrm{~m}$ de comprimento, graduada em centímetros, fazendo-se 50 leituras a cada sete dias em cada unidade experimental. Para a estimativa da altura do dossel, foi considerada a extremidade ou o ponto de curvatura da lâmina da folha mais alta como o local da amostragem, no nível do solo.

As taxas de acúmulo de massa seca (TAMS) foram estimadas pela técnica do triplo emparelhamento (Moraes et al., 1990). Neste método, escolhemse duas áreas similares que estão sob pastejo e outra para locação da gaiola de exclusão. Vinte e oito dias após este procedimento, foi realizado o corte das áreas dentro e fora da gaiola marcadas na avaliação anterior. Foram utilizadas duas gaiolas por piquete. $\mathrm{O}$ cálculo da TAMS foi realizado segundo Campbell (1966). Para determinar o acúmulo de MS de forragem, foram utilizadas as TAMS estimadas em cada período de avaliação multiplicados pelo número de dias.

A estimativa da MF foi realizada a cada 28 dias, conforme o método da dupla amostragem (Wilm et al. 1944), e, para o cálculo da MF, foi utilizada a equação proposta por Gardner (1986). A forragem colhida durante a dupla amostragem foi separada em lâmina verde, colmo + bainha verde e material morto para determinação do percentual dos componentes morfológicos. Posteriormente, as amostras foram secas em estufa de circulação forçada de ar por 72 horas a $55^{\circ} \mathrm{C}$. O percentual de cada componente morfológico multiplicado pela MF permitiu a estimativa da massa de lâminas verdes/ha (MLV), massa de colmos + bainhas verdes/ha (MCV) e massa de material morto/ha (MMM). A massa de forragem

R. Bras. Zootec., v.33, n.6, p.1949-1958, 2004 (Supl. 2) 
verde/ha (MFV) foi obtida subtraindo-se da MF a MMM. A porcentagem da área de solo descoberto e porcentagem de solo coberto com liteira foram avaliadas em proporção de área coberta ou não, simultaneamente à dupla amostragem.

Para determinação do índice de área foliar, foi coletado material vegetativo em cinco áreas de $0,25 \mathrm{~m}^{2}$, representativa da condição média do piquete no momento da amostragem. Foram retiradas, em cada amostra, dez lâminas de folhas expandidas e separadas três porções (inferior, média e superior) de 2x3 $\mathrm{cm}$ de cada folha. Estas porções foram secas em estufa de $60^{\circ} \mathrm{C}$ para determinação do peso foliar específico, que, após, foi relacionado ao peso seco total das folhas e à área de solo para obtenção do IAF/ha, conforme Peterson (1970).

Os dados experimentais foram analisados estatisticamente pela análise de regressão, utilizandose o programa SAEG (UFV, 1993), adotando-se a metodologia de superfície de resposta, a partir do modelo polinomial quadrático, em função das duas variáveis independentes. O modelo estatístico para análise dos resultados na pastagem foi:

$$
\hat{\mathrm{Y}}_{\mathrm{ijk}}=\mu+\mathrm{b}_{1} \mathrm{~A}_{\mathrm{i}}+\mathrm{b}_{2} \mathrm{~A}_{\mathrm{i}}{ }^{2}+\mathrm{b}_{3} \mathrm{~T}_{\mathrm{j}}+\mathrm{b}_{4} \mathrm{~T}_{\mathrm{j}}{ }^{2}+\mathrm{b}_{5} \mathrm{AT}_{\mathrm{ij}}+\mathrm{e}_{\mathrm{ijk}}
$$

em que $\hat{\mathrm{Y}}_{\mathrm{ijk}}=$ valor observado das variáveis, no piquete $j$, recebendo tratamento $i ; \mu=$ constante geral; $\mathrm{A}=$ altura do dossel; $\mathrm{T}$ = efeito do dia de avaliação; $\mathrm{b}_{1}=$ coeficiente linear da regressão da variável $\hat{\mathrm{Y}}$, em função da altura do dossel; $b_{2}=$ coeficiente quadrático da regressão da variável $\mathrm{Y}$, em função da altura do dossel; $b_{3}=$ coeficiente linear da regressão da variável $\hat{\mathrm{Y}}$, em função do dia de avaliação; $\mathrm{b}_{4}=$ coeficiente quadrático da regressão da variável $\hat{Y}$, em função do tempo; $b_{5}=$ coeficiente da variável $\hat{Y}$, em função da interação entre altura e tempo; eijk = erro aleatório associado a cada observação Yijk.

\section{Resultados e Discussão}

A massa de lâminas verdes (MLV), obtida nas alturas de dossel e períodos de avaliação, está apresentada na Figura 1. Os resultados revelam efeitos $(P<0,05)$ em relação às alturas do pasto e aos períodos de avaliação. A MLV diminuiu com o período de avaliação em todos os tratamentos e aumentou com a altura do pasto. No início de janeiro e no final de abril, a MLV foi de 1.430 e 730, 3.690 e 3.000 kg/ha de MS, respectivamente, em função das alturas ex- tremas (20 e $80 \mathrm{~cm}$ ). A redução da MLV foi mais acentuada nos pastos mantidos mais baixos, pois, nessas alturas, há maior proporção de folhas removidas pelo pastejo e menores taxas de crescimento (Bircham \& Hodgson, 1983). A porcentagem de lâminas verdes sempre ficou acima de $30 \%$ da massa de forragem, independentemente da altura do dossel. Os valores encontrados de MLV são superiores aos relatados por Euclides et al. (1993) para a mesma gramínea. Com capim-elefante anão, Almeida (1997) observou maior MLV com o aumento da oferta de forragem. A redução na MLV ao longo do período de avaliação se deve à diminuição da temperatura e da precipitação (Tabela 1) e, principalmente, ao fato de, na avaliação de abril, as plantas estarem no início do período reprodutivo, com alongamento dos entrenós, promovendo aumento da massa de colmos + bainhas verdes e redução da massa de lâmina foliar verde (Monteiro \& Moraes, 1996).

A massa de colmos + bainhas verdes (MCV) apresentou incremento linear $(P<0,05)$, em função das alturas de dossel e do dia de avaliação (Figura 2). Com o aumento na altura do dossel, a MCV elevou-se, corroborando os resultados de Almeida et al. (2000), que, trabalhando com capim-elefante anão em quatro ofertas de forragem, obteve maior massa de colmo + bainha verde nos pastos mantidos em ofertas de forragem maiores.

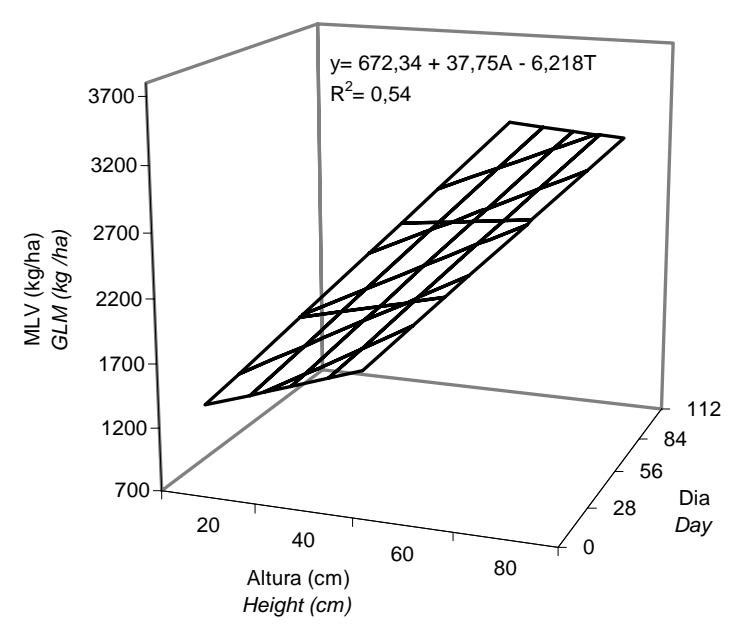

Figura 1 - Massa de lâmina foliar verde (MLV) do capim-Tanzânia, em função da altura de dossel $(A)$ e do dia de avaliação (T).

Figure 1 - Mass of green leaf blade (GLM) of Tanzaniagrass, according to sward height $(A)$ and evaluation day $(T)$. 
Nas Figuras 1 e 2, pode-se observar que a MLV e MCV apresentaram relação inversa na pastagem, porque, inicialmente, havia maior MLV e menor MCV. Entretanto, ao longo do período de avaliação, as mesmas foram se alterando, porque os colmos de maior idade são mais lignificados, com entrenós alongados, e, portanto são mais pesados que as folhas. Fagundes et al. (1999a), avaliando intensidades de pastejo e a composição morfológica de pastos de Cynodon spp., encontraram aumento dos valores de haste no pasto, à medida que o período de coleta avançou, comportamento inverso daquele verificado para folhas.

A massa de material morto (MMM), obtida nas alturas do dossel e nos dias de avaliação, está demonstrada na Figura 3. O aumento da altura de dossel promoveu efeito quadrático $(\mathrm{P}<0,05)$ na MMM, que se elevou com o avançar do período de avaliação. A MMM foi crescente até a altura de dossel de 60 $\mathrm{cm}$, com queda na altura $80 \mathrm{~cm}$. A MMM do pasto foi obtida por meio da porcentagem de material morto presente no dossel, com valores médios variando de 40 a $34 \%$ para as alturas de 20 e $65 \mathrm{~cm}$, respectivamente, evidenciando que grande quantidade da massa de forragem produzida não era consumida pelos animais, mas retornava ao sistema como liteira. No período de avaliação de janeiro a abril, foi observado efeito linear crescente $(\mathrm{P}<0,05)$ para todas as alturas de dossel. O aumento da MMM ao longo das avalia-

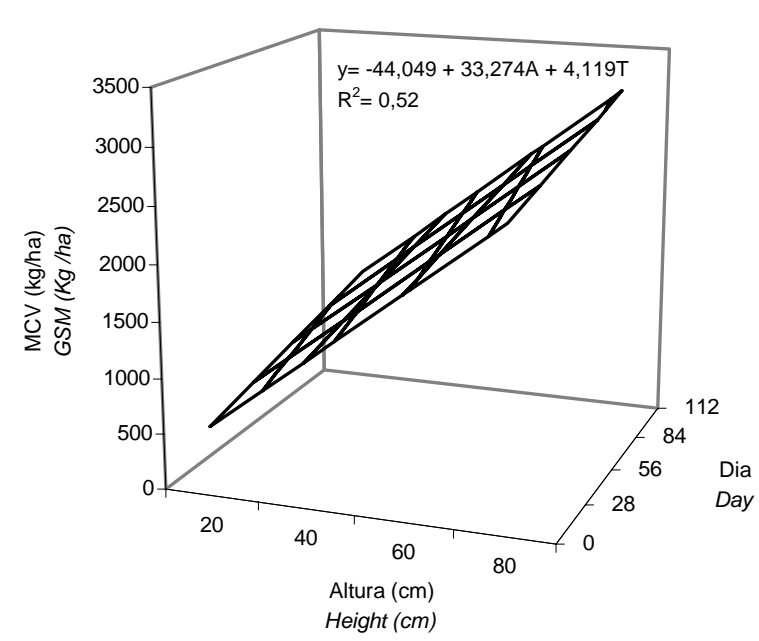

Figura 2 - Massa de colmo + bainha verde (MCV) do capim-Tanzânia, em função da altura do dossel $(A)$ e do dia de avaliação $(T)$.

Figure 2 - Mass of green stem + leaf sheath (GSM) of Tanzaniagrass, according to sward height $(A)$ and evaluation day $(T)$.

R. Bras. Zootec., v.33, n.6, p.1949-1958, 2004 (Supl. 2) ções pode ser atribuído às mudanças nas porções folha verde e colmo verde das plantas e no material senescente, provavelmente graças a fatores fisiológicos ligados à morte e decapitação de perfilhos, fato também observado por Moraes \& Maraschin (1988), em pastagem de milheto.

A massa de forragem (MF) apresentou comportamento linear positivo $(\mathrm{P}<0,05)$ em resposta às alturas de dossel (Figura 4), corroborando os resultados obtidos por Bortolo (1999), Fagundes et al. (1999a) e Grise et al. (2001), que observaram, em pastos mantidos mais altos, maiores valores de massa de forragem. Durante o período de avaliação, não foi evidenciada diferença $(P>0,05)$ para $\mathrm{MF}$, demostrando que o manejo do pastejo pela altura do dossel forrageiro constitui-se uma forma eficiente de monitorar a massa de forragem presente na pastagem.

A massa de forragem verde (MFV) apresentou comportamento semelhante à massa de forragem (MF) (Figura 4).

A MFV elevou-se $(\mathrm{P}<0,05)$ com o aumento da altura do dossel e manteve-se estável ao longo do período de avaliação. Os valores médios encontrados foram 1560 e $5820 \mathrm{~kg}$ de MS/ha nas alturas de 20 e $65 \mathrm{~cm}$ de dossel, respectivamente. A participação da MFV foi de 56, 63, 66 e 67\% da MF para as alturas de dossel de 20, 40, 50 e $65 \mathrm{~cm}$, respectivamente. A partir dos valores obtidos para MFV, pode-se inferir que as perdas por senescência, por pastejo e morte

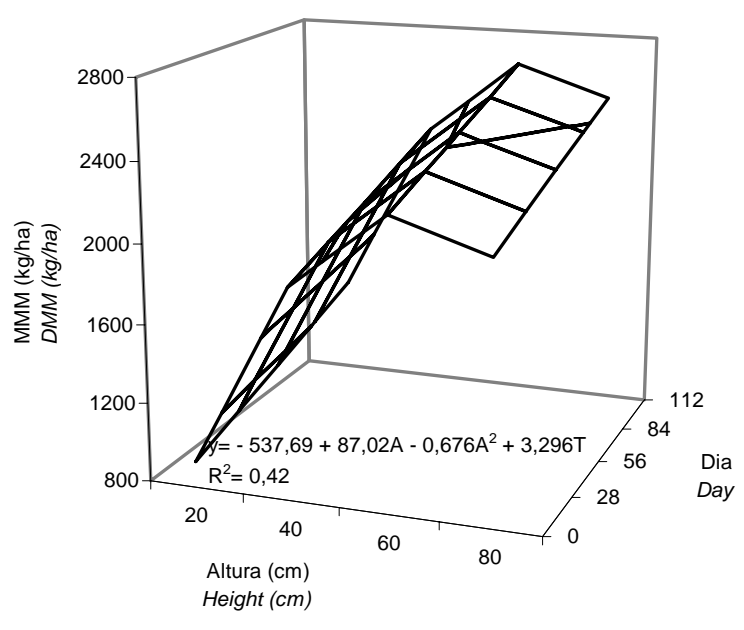

Figura 3 - Massa de material morto (MMM) do capimTanzânia, em função da altura de dossel (A) e do dia de avaliação $(T)$.

Figure 3 - Dead matter mass (DMM) of Tanzaniagrass, according to sward height $(A)$ and evaluation day $(T)$. 
dos tecidos da forragem foram elevadas, atingindo valores médios próximos a 35\%. Resultados semelhantes foram obtidos por Pepiliasco (2000) e Cecato et al. (2001), ao trabalharem com capim-Tanzânia manejado por controle da altura do dossel forrageiro. Embora para a menor e maior alturas de dossel tenha correspondido à maior e menor porcentagens de material morto (Figura 8), os valores de massa de material morto foram quase o dobro para a maior altura de dossel (Figura 3). Isto ocorre porque, segundo Hodgson (1990) e Pinto et al. (2001), quanto maior a MF, maiores as perdas por senescência, conseqüência da baixa utilização da forragem produzida.

$\mathrm{O}$ índice de área foliar (IAF) correspondente às alturas de dossel e ao período de avaliação encontra-se na Figura 5. Houve efeito $(\mathrm{P}<0,05)$ para as alturas de dossel e para o período de avaliação, pois o IAF elevou-se $(\mathrm{P}<0,05)$ com aumento da altura do dossel. Os valores para as alturas superiores foram bem mais elevados que para as alturas inferiores. Fagundes et al. (1999b) observaram que pastos mantidos mais altos apresentaram maiores valores de IAF. A MLV média encontrada neste trabalho (Figura 1) foi maior que aquela relatada por Euclides et al. (1993) e Zimmer (1999), para Panicum, o que provavelmente contribuiu para valores de IAF elevados.

Ao longo do período de avaliação, o IAF apresentou comportamento quadrático $(\mathrm{P}<0,05)$. Inicialmente, o IAF estava baixo, elevando-se no período

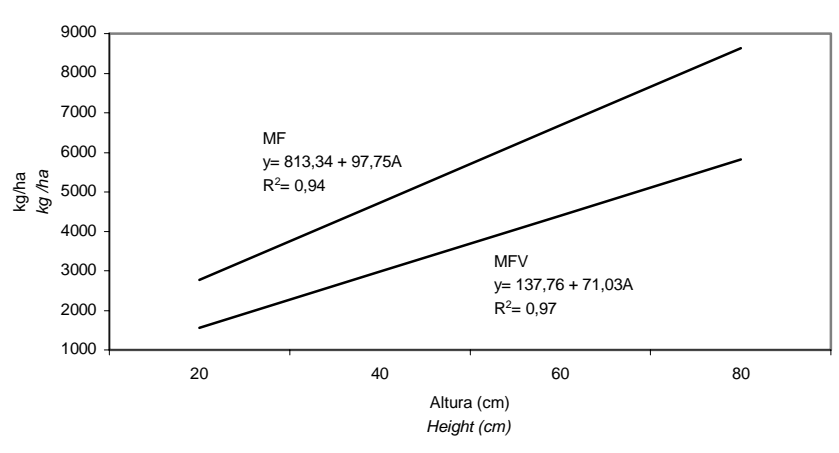

Figura 4 - Massa de forragem (MF) e massa de forragem verde (MFV) do capim-Tanzânia, em função da altura do dossel forrageiro (A).

Figure 4 - Herbage mass (HM) and green herbage mass (GHM) of Tanzaniagrass, according to sward height (A). intermediário e reduzindo no período final. Este comportamento provavelmente reflete as condições de ambiente e o efeito da adubação nitrogenada parcelada, uma vez que, no mês de fevereiro, foram aplicados mais de $50 \%$ do nitrogênio e ocorreram as mais elevadas precipitações (Tabela 1 ), propiciando o crescimento de folhas. No início e no final do período de avaliação, o IAF foi de 1,52 e 0,98 e 7,09 e 6,56 , respectivamente, nas pastos de alturas extremas (20 e $80 \mathrm{~cm})$.

A taxa de acúmulo de massa seca (TAMS) apresentou efeito linear crescente $(\mathrm{P}<0,05)$ para as alturas de dossel (Figura 6). A maior TAMS, com o incremento em altura do dossel, esteve associada ao maior IAF naquelas condições (Figura 5), e o IAF do dossel, estando próximo do ótimo, favorece a interceptação eficiente de luz e, conseqüentemente, a produção de forragem. Embora em pastos mais altos tenha ocorrido maior TAMS, esta estimativa foi realizada a cada 28 dias, utilizando-se gaiolas de exclusão. Observou-se, no momento do corte, grande proporção de folhas e de colmos finos na menor altura de dossel, enquanto, na maior altura, grande proporção de colmos grossos e pesados, o que pode ter favorecido os altos valores de TAMS nas maiores alturas de dossel forrageiro.

Outro fator que pode ter contribuído para os altos valores de TAMS foi o acréscimo da MLV e da MCV (Figuras 1 e 2) com o aumento da altura do dossel.

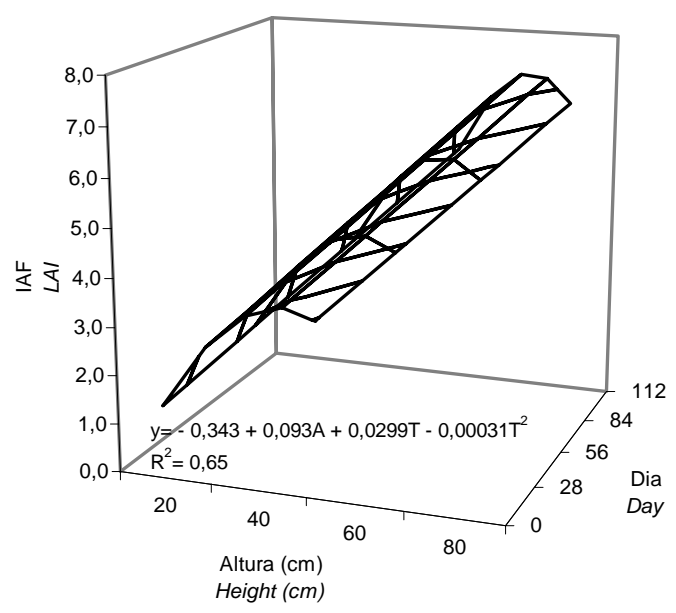

Figura 5 - Índice de área foliar (IAF) do capim-Tanzânia em função da altura do dossel $(A)$ e do dia de avaliação $(T)$.

Figure 5 - Leaf area index (LAI) of Tanzania grass, according to sward height $(A)$ and evaluation day $(T)$.

R. Bras. Zootec., v.33, n.6, p.1949-1958, 2004 (Supl. 2) 
Santos et al. (1999) observaram TAMS, para a cultivar Tanzânia, de 79,8; 128,2; 150,1 e 96,1 kg de MS/ha/dia para as épocas setembro/novembro, novembro/dezembro, janeiro/fevereiro e fevereiro/abril, respectivamente. Almeida et al. (2000), trabalhando com capim-elefante anão, obteve 59,0; 93,6; 149,2 e $159,4 \mathrm{~kg}$ de MS de lâminas verdes/ha/dia para ofertas de forragem de 3,8; 7,5; 10,5 e 14,7 kg de MS/100kg de $P V$, respectivamente.

Para a altura de dossel e para o período de avaliação (Figura 7), o acúmulo de forragem (AF) apresentou comportamento linear crescente $(\mathrm{P}<0,05)$. $\mathrm{O}$ aumento na altura do dossel acarretou incremento no $\mathrm{AF}$, o que era esperado, uma vez que o AF é função da TAMS, que elevou linearmente com o avanço da em altura do dossel. A MLV observada durante o período de avaliação, assim como as alturas (Figura 1), determinaram maior IAF para as alturas superiores, promovendo, conseqüentemente, maiores TAMS e AF. O AF, durante o período de avaliação, também aumentou $(\mathrm{P}<0,05)$. Este foi de $8.600,13.100$, 17.500 e $21.950 \mathrm{~kg}$ de MS/ha para as alturas 20, 40, 60 e $80 \mathrm{~cm}$ do pasto, respectivamente.

Os valores de AF foram superiores aos encontrados por Santos et al. (1999) e Gerdes et al. (2000) para o capim-Tanzânia. Todavia, estes foram próximos aos de Cecato et al. (2000), que obtiveram $16 \mathrm{t} /$ ha de MS para o capim mantido a $40 \mathrm{~cm}$.

A porcentagem de material morto (MM) apresentou avanço linear $(\mathrm{P}<0,05)$ para altura de dossel e

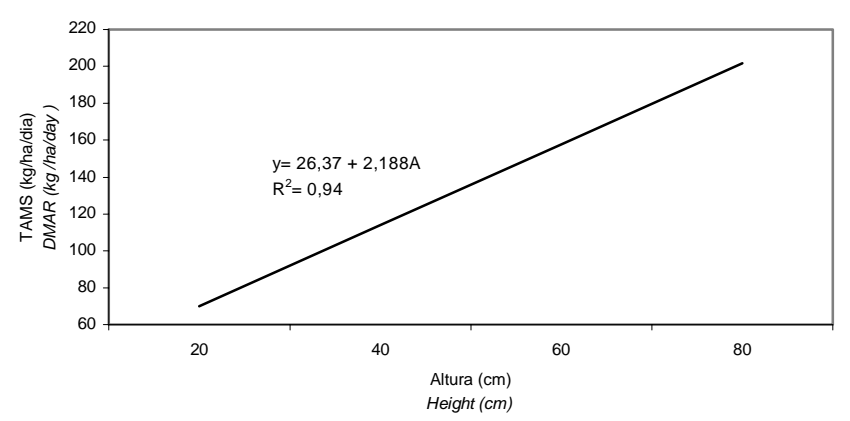

Figura 6 - Taxa de acúmulo de matéria seca (TAMS) do capim-Tanzânia, em função da altura de dossel (A).

Figure 6 - Dry matter accummulation rate (DMAR) of Tanzaniagrass, according to sward height (A). linear crescente $(\mathrm{P}<0,05)$ para o período de avaliação em todas as alturas estudadas (Figura 8). O elevado percentual de material morto, com a diminuição da altura do dossel, pode estar associado à decapitação de perfilhos, promovendo sua morte e, principalmente, ao efeito do pisoteio dos animais. Isto porque na menor altura de dossel forrageiro, a pastagem pode estar sendo intensivamente desfolhada, com baixa oferta de forragem, determinando a necessidade de os animais se deslocarem por toda a extensão da áreas para suprirem suas exigências de ingestão de MS, resultando em maior perda física de forragem (Cecato et al., 2001).

$\mathrm{O}$ aumento da porcentagem de MM durante o período para todas as alturas estudadas pode ter sido em função da morte de perfilhos (folhas senescentes, mortas e colmos mortos) durante as avaliações, favorecendo o avanço do percentual. Bortolo (1999), avaliando uma pastagem de Coastcross-1 (Cynodon dactylon (L.) Pers) sob diferentes níveis de matéria seca residual, observou que a porcentagem de material morto decresceu linearmente à medida que se aumentou a massa de forragem, mas elevou-se no decorrer dos dias de avaliação.

As porcentagens de solo descoberto (SD) e de solo coberto com liteira (SCL) são apresentadas na Figura 9. As porcentagem de SD e de SCL decresceram linearmente $(\mathrm{P}<0,05)$ à medida que aumentou a altura do dossel, sendo que foi semelhante $(\mathrm{P}>0,05)$ durante o período de avaliação. As porcentagens de

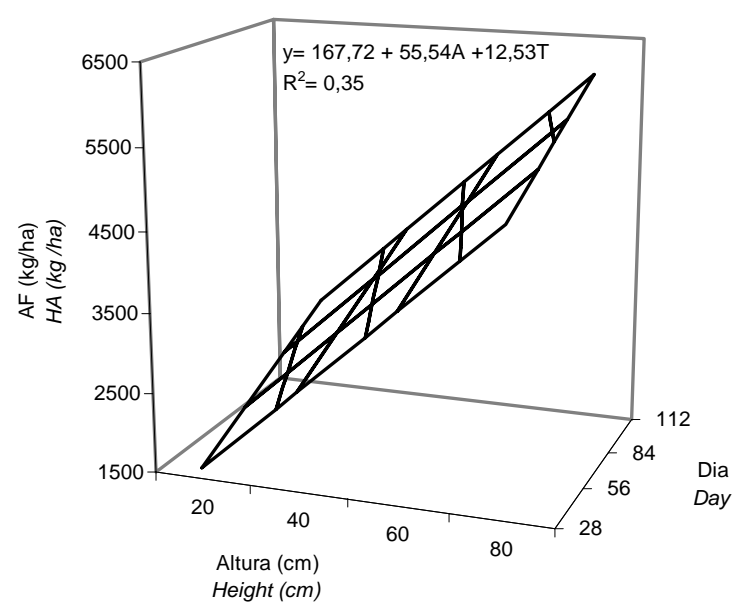

Figura 7 - Acúmulo de forragem (AF) do capim-Tanzânia, em função da altura do dossel (A) e do dia de avaliação (T).

Figure 7 - Herbage acummulation (HA) of Tanzaniagrass, according to sward height and evaluation day.

R. Bras. Zootec., v.33, n.6, p.1949-1958, 2004 (Supl. 2) 


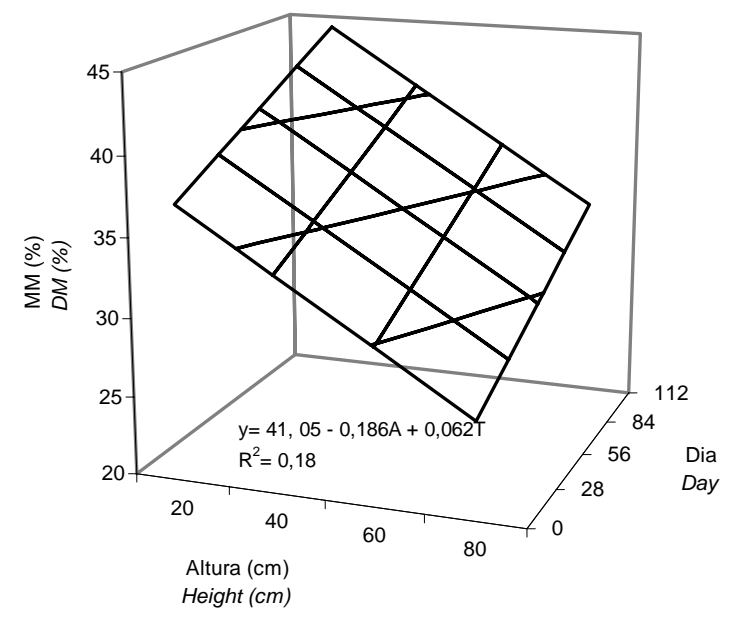

Figura 8 - Porcentagem de material morto (MM) do capim-Tanzânia, em função da altura de dossel (A) e do dia de avaliação (T).

Figure 8 - Dead matter percentage (DM) of Tanzaniagrass, according to sward height (At) and evaluation day (T).

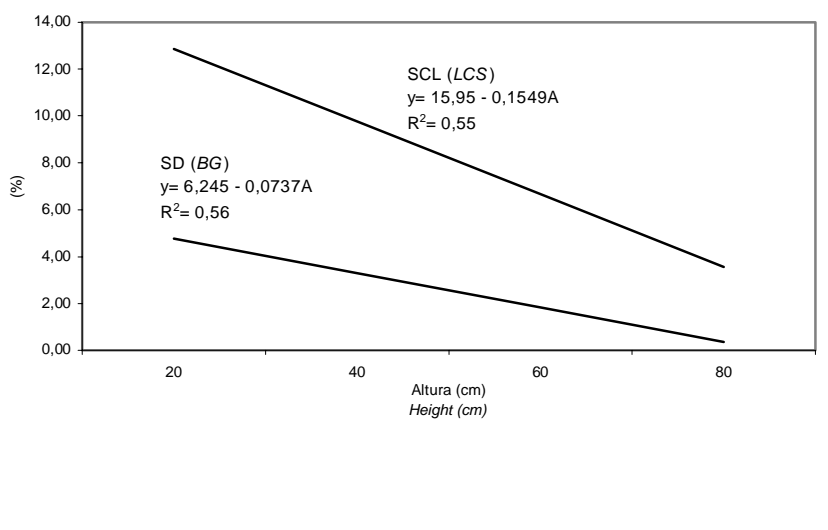

Figura 9 - Porcentagem de área de solo descoberto (SD) e de solo coberto com liteira (SCL) do capim-Tanzânia, em função da altura de dossel (A).

Figure 9 - Proportion of bare ground (BG) and soil covered by litter (LCS) of Tanzaniagrass, according to sward height $(A)$.

em menor proporção SCL/SD com pasto a $80 \mathrm{~cm}$.

\section{Conclusões}

valores de SD podem ser atribuídos aos bons níveis de MF mantidos em todos os tratamentos. A maior porcentagem de SD na menor altura de dossel foi decorrente da menor MF e da maior intensidade de pastejo para manter a altura desejada nas unidades experimentais. Cecato et al. (2001) não encontraram diferença na área de solo descoberto em pastagem de capim-Tanzânia manejada em diferentes alturas de dossel. Todavia, os valores médios foram superiores aos encontrados neste trabalho. A falta de significância para a proporção de SD neste experimento pode ser atribuída à MF mantida constante durante o período, promovendo boa cobertura do solo e evitando o processo de degradação da pastagem.

A porcentagem de solo coberto com liteira (SCL) apresentou valores de 12,8; 9,8; 6, 7 e 3,6\% para as alturas de 20, 40, 60 e $80 \mathrm{~cm}$ de dossel, respectivamente. A diminuição da proporção de SCL com o aumento da altura do dossel ocorreu porque nas maiores alturas a estrutura do dossel cobria quase todo o solo e, durante a avaliação, pouca liteira foi possível de ser observada, explicando os baixos valores encontrados com o aumento da altura do dossel.

A análise conjunta dos valores de SCL e SD indica redução mais acentuada na área descoberta do pasto manejado a 20 para $80 \mathrm{~cm}$ de altura, que resulta 
Dissertação (Mestrado em Zootecnia) - Universidade Estadual de Maringá, 1999.

BRÂNCIO, P.A.; NASCIMENTO JR., D.; EUCLIDES, V.P.B. et al. Avaliação de três cultivares de Panicum maximum Jacq. sob pastejo. 1. Disponibilidade de forragem, altura e profundidade pastejada. In: REUNIÃO ANUAL DA SOCIEDADE BRASILEIRA DE ZOOTECNIA, 36., 2000, Viçosa, MG. Anais... Viçosa, MG: Sociedade Brasileira de Zootecnia, 2000, p.41.

CAMPBELL, A.G. Grazed pastures parameters; I. Pasture drymatter production and availability in a stocking rate and grazing management experiment with dairy cows. Journal of Agricultural Science, v.67, n.2, p.211-216, 1966.

CANTO, M.W.; CECATO, U.; PETERNELLI, M. et al. Efeito da altura do capim-Tanzânia diferido nas características da pastagem no período do inverno. Revista Brasileira de Zootecnia, v.30, n.4, p.1186-1193, 2001.

CARVALHO, C.A.B.; SILVA, S.C.; SBRISSIA, A.F. et al. Demografia do perfilhamento e taxas de acúmulo de matéria seca em coastcross submetido a pastejo. Scientia Agricola, v.36, n.3, p.567-575, 2001.

CECATO, U. Influência da freqüência de corte, níveis e formas de aplicação do nitrogênio sobre a produção, composição química e algumas características da rebrota do capimAruana (Panicum maximum Jacq. cv. Aruana). Jaboticabal: Universidade Estadual Paulista, 1993. 112p. Tese (Doutorado em Produção Animal) - Universidade Estadual Paulista, 1993.

CECATO, U.; CASTRO, C.R.C.; CANTO, M.W. et al. Perdas de forragem em capim-Tanzânia (Panicum maximum Jacq cv. Tanzânia-1) manejado sob diferentes alturas sob pastejo. Revista Brasileira de Zootecnia, v.30, n.2, p.295-301, 2001.

CECATO, U.; MACHADO, A.O.; MARTINS, E. N. et al. Avaliação da produção e de algumas características fisiológicas de cultivares e acessos de Panicum maximum Jacq. sob duas alturas de corte. Revista Brasileira de Zootecnia, v.29, n.3, p.660-668, 2000. CORRÊA, A.R. Forrageiras: aptidão climática do Estado do Paraná. In: MONTEIRO, A.L.G.; MORAES, A.; CORRÊA, E.A.S. et al. (Eds.) Forragicultura no Paraná. Londrina: CPAF, 1996. p.15-22.

CORSI, M., SANTOS, P.M. Potencial de Produção do Panicum maximum. In: SIMPÓSIO SOBRE MANEJO DE PASTAGENS, 12., 1995, Piracicaba. Anais... Piracicaba: Fundação de Estudos Agrários Luiz de Queiroz, 1995. p.275303.

EMBRAPA. Centro Nacional de Pesquisa de Solos (Rio de Janeiro, RJ). Sistema brasileiro de classificação de solos. Brasília: Embrapa Produção de Informação io de Janeiro: Embrapa solos, 1999. 412p.

EUCLIDES, V.P.B.; MACEDO, M.C.M.; ZIMMER, A.H. et al. Evaluation of Panicum maximum cultivars under grazing. In: INTERNATIONAL GRASSLAND CONGRESS, 17., 1993, New Zealand. Proceedings... Palmerston North: New Zealand Grassland Association, 1993. p.1999-2000.

EUCLIDES, V.P.B. Valor alimentício de espécies forrageiras do gênero Panicum. In: SIMPÓSIO SOBRE MANEJO DA PASTAGEM,12., 1995, Piracicaba. Anais...Piracicaba: Fundação de Estudos Agrários Luiz de Queiroz, 1995. p.245-273.

FAGUNDES, J.L.; SILVA, S.C.; PEDREIRA, C.G.S. et al. Índice de área foliar, interceptação luminosa e acúmulo de forragem em pastagens de Cynodon spp. Sob diferentes intensidades de pastejo. Scientia Agricola, v.56, n.4, p.1141-1150, 1999b.

FAGUNDES, J.L.; SILVA, S.C.; PEDREIRA, C.G.S. et al. Intensidades de pastejo e a composição morfológica de pastos de Cynodon spp. Scientia Agricola, v.56, n.4, 1999a.

R. Bras. Zootec., v.33, n.6, p.1949-1958, 2004 (Supl. 2)
FORBES, T.D.A. Researching the plant-animal interface: the investigation of ingestive behaviour in grazing animals. Journal of Animal Science, v.66, n.9, p.2369-2379, 1988.

GARDNER, A.L. Técnicas de pesquisa em pastagens e aplicabilidade de resultados em sistemas de produção. Brasília: Embrapa, 1986. 197p.

GERDES, L.; WERNER, J.C.; COLOZZA, M.T. et al. Avaliação de características de valor nutritivo das gramíneas forrageiras Marandu, Setária e Tanzânia nas estações do ano. Revista Brasileira de Zootecnia, v.29, n.4, p.955-963, 2000.

GRISE, M.M.; CECATO, U.; MORAES, A. et al. Avaliação da Composição química e da digestibilidade in vitro da mistura de Aveia IAPAR 61 (Avena strigosa Schreb) + ervilha forrageira (Pisum arvense L.) em diferentes alturas sob pastejo. Revista Brasileira de Zootecnia, v.30, n.3, p.659-665, 2001.

HERLING, V.R. Efeitos de níveis de nitrogênio sobre algumas características fisiológicas e qualitativas dos cultivares colonião e centenário (Panicum maximum Jacq.). Jaboticabal, Universidade Estadual Paulista, 1995. 125p. Tese (Doutorado em Zootecnia) - Universidade Estadual Paulista, 1995.

HODGSON, J. Grazing management. Science into practice. Palmerston North: Longman, 1990. 203p.

HUMPHREYS, L. R. Defoliation and regrowth. In: STOBBS, T.H. (Ed.) Management of improved tropical pastures. Queesland: Institute Agricultural Science, 1975. p.28-38.

HUMPHREYS, L.R. Tropical pastures and fodder crops. Londres: Longman. 1978. 135p.

LEMAIRE, G. Ecophysiology of grasslands: dynamics aspects of forage plant populations in grazed swards. INTERNATIONAL GRASSLAND CONGRESS, 19., São Pedro, 2001. Proceedings... São Pedro: 2001. p.29-37.

MACHADO, A.O.; CECATO, U.; MIRA, R.T. et al. Avaliação da composição química e digestibilidade in vitro da matéria seca de cultivares e acessos de Panicum maximum Jacq. sob duas alturas de corte. Revista Brasileira de Zootecnia, v.27, n.5, p.10571063, 1998.

MARASCHIN, G.E. Avaliação de forrageiras e rendimento de pastagens com o animal em pastejo. In: SIMPÓSIO INTERNACIONAL DE FORRAGICULTURA. REUNIÃO ANUAL DA SOCIEDADE BRASILEIRA DE ZOOTECNIA, 31., 1994, Maringá. Anais... Maringá: Universidade Estadual de Maringá, 1994. p.65-98.

MONTEIRO, A.L.; MORAES, A. Fisiologia e morfologia de plantas forrageiras. In: MONTEIRO, A.L.; MORAES, A.; CORREA, E.A.S. et al. (Eds.) Forragicultura no Paraná. Londrina: CPAF, 1996. p.75-92.

MORAES, A.; MARASCHIN, G.E. Pressões de pastejo e produção animal em milheto cv. comum. Pesquisa Agropecuária Brasileira, v.23, n.2, p.197-205, 1988.

MORAES, A.; MOOJEN, E.L.; MARASCHIN, G.E. Comparação de métodos de estimativa de taxas de crescimento em uma pastagem, submetida a diferentes pressões de pastejo. In: REUNIÃO DA SOCIEDADE BRASILEIRA DE ZOOTECNIA, 27., 1990, Campinas. Anais... Campinas: Sociedade Brasileira de Zootecnia, 1990. p.813- 832.

MOTT, G. O.; LUCAS, H. L. The design, conduct and interpretation of grazing trials on cultivated and improved pastures. In: INTERNATIONAL GRASSLAND CONGRESS, 6., 1952, Pensylvania. Proceedings... Pensylvania: State College Press, 1952. p.1380-1385.

MOTT, G.O.; MOORE, J.E. Evaluated forage production. In: HEATH, M.E.; BARNES, R.F.; METCALFE, D.S. (Eds.) 
Forages the science of grassland agriculture. 4.ed. Ames: Iowa State University, 1985. p.422-429.

PARSONS, A.J.; LEAFE, E.L.; COLLET, B. et al. The physiology of grass production under grazing. 1. Characteristics of leaf and canopy photosynthesis of continuously grazed swards. Journal of Applied Ecology, v.20, n.1, p.117-126, 1983.

PENNING, P.D.; PARSONS, A.J.; ORR, R.J. et al. Intake and behavior responses by sheep to changes in sward characteristiques under rotational grazing. Grass and Forrage Science, v.49, p.476-486, 1991.

PEPILIASCO, L.S. Perdas de forragem e acúmulo de liteira em capim-Tanzânia (Panicum maximum Jacq cv. Tanzânia-1) pastejado em diferentes alturas. Maringá: Universidade Estadual de Maringá, 2000. 18p. (Trabalho de Graduação em Zootecnia) - Universidade Estadual de Maringá, 2000.

PETERSON, R.A. Efeito do corte ou pastoreio sobre as plantas. In: Fundamentos de manejo de pastagens. São Paulo: Instituto de Zootecnia. 1.ed. 1970. p.37-62.

PINTO, L.F.M., SILVA, S.C.; SBRISSIA, A.F. et al. Dinâmica do Acúmulo de Matéria Seca em Pastagens de Tifton 85 Sob Pastejo. Scientia Agricola, v.58, n.3, p.439-447, 2001.

REGO, F.C.A. Avaliação da qualidade, densidade e características morfológicas do capim-Tanzânia (Panicum maximum Jacq cv. Tanzânia-1) manejado em diferentes alturas, sob pastejo. Maringá: Universidade Estadual de Maringá, 2001. 90p. Dissertação (Mestrado em Zootecnia) Universidade Estadual de Maringá, 2001.
SANTOS, P.M.; CORSI, M.; BALSALOBRE, M.A.A. Efeito da Frequência de pastejo e da época do ano sobre a produção e a qualidade em Panicum maximum cvs. Tanzânia e Mombaça. Revista Brasileira de Zootecnia, v.28, n.2, p.244-249, 1999.

UNIVERSIDADE FEDERAL DE VIÇOSA - UFV. Sistema para análises estatísticas e genéticas - SAEG. Viçosa, MG: 1993.

WILM, H.G.; COSTELO, O.F.; KLIPPLE, G.E. Estimating forage yield by the double sampling method. Journal American of Society Agronomic, v.36, n.1, p.194-203, 1944.

ZIMMER, A.H. Efeito de níveis de nitrogênio e resíduos de pastejo, sobre a produção, estrutura e qualidade das cultivares Aruana e Vencedor de (Panicum maximum Jacq.). Jaboticabal: Universidade Estadual Paulista, 1999. 213p. Tese (Doutorado em Zootecnia) - Universidade Estadual Paulista, 1999.

Recebido em: 28/10/03

Aceito em: 28/05/04 